\title{
Study on knowledge and practice of screening for cervical cancer among women from rural communities in central Kerala, India
}

\author{
Megha Jayaprakash ${ }^{1}$, Georgy Joy Eralil ${ }^{2 *}$, Rajany Jose ${ }^{3}$, \\ Radha K. R. ${ }^{4}$, Vijilakshmi A. G. ${ }^{1}$, P. G. Ambikabhai ${ }^{2}$
}

\begin{abstract}
${ }^{1}$ Department of Obstetrics and Gynecology, Government Medical College, Thrissur, Kerala, India
${ }^{2}$ Department of Obstetrics and Gynecology, Sree Narayana Institute of Medical Sciences, Kerala, India

${ }^{3}$ Department of Community Medicine, Government Medical College, Thrissur, Kerala, India

${ }^{4}$ Department of obstetrics and gynecology, Government medical college Kochi, Kerala, India
\end{abstract}

Received: 08 August 2018

Accepted: 04 September 2018

\author{
*Correspondence: \\ Dr. Georgy Joy Eralil, \\ E-mail: georgyeralil@yahoo.co.in
}

Copyright: (c) the author(s), publisher and licensee Medip Academy. This is an open-access article distributed under the terms of the Creative Commons Attribution Non-Commercial License, which permits unrestricted non-commercial use, distribution, and reproduction in any medium, provided the original work is properly cited.

\begin{abstract}
Background: Early detection of cervical cancer is possible with Pap smear tests. The proportion of women who undergo Pap smear testing ranges from $68 \%$ to $84 \%$ in developed countries as compared to India where the rates range from $2.6 \%$ to $6.9 \%$ among women in communities. This study is to assess the knowledge of women about cervical cancer, its screening, role of doctor and source of information.

Methods: Cross-sectional study - observational study of Women attending gynecology camps/op clinics held in rural areas of Ernakulam and Thrissur who are between 25 and 65 years of age Non-random sampling with Sequential inclusion of the women who met the study criteria. A questionnaire devised collecting Basic sociodemographic profile like age, parity, educational qualification, Questions to assess knowledge about symptoms of cervical cancer Questions to assess the knowledge about cervical cancer screening and prevention doctor as Source of knowledge from the subjects. Correct response for questions carried score of 1 mark. So, the maximum was 6 and minimum was 0 . The knowledge was graded as: $<2$ being poor knowledge; $2-5$ being satisfactory knowledge and $\geq 5$ being good knowledge.

Results: $32.9 \%$ of women identified discharge per vaginum as the most common symptom. When $50.9 \%$ thought multiparity was a risk factor $30 \%$ identified early sexual activity. $2.3 \%$ women knew that pas smear screening has to be done repeatedly. $8.3 \%$ of participants already had screening done. Only $8.3 \%$ of doctors advised pap screening during their consultations. Uptake of pap smear after awareness program was $100 \%$.

Conclusions: Awareness classes are needed for increasing the coverage for pap smear screening. The women should be educated about cervical cancer, its screening methods and the facilities available for screening in the hospitals. An Information Leaflet has to be provided to these women in the local language. Training programs should be conducted for general practitioners and gynecologists to conduct awareness classes for the public and also to motivate women to undergo screening at every possible opportunity.
\end{abstract}

Keywords: Cancer cervix screening, Human papilloma virus, HPV vaccine Pap smear

\section{INTRODUCTION}

Cervical cancer is one of the most common cancers worldwide. In India, it is one the leading causes of mortality among women accounting for $23.3 \%$ of all cancer deaths. ${ }^{1}$ India accounts for about $20 \%$ of cervical cancer cases reported from the world. ${ }^{2}$ More than threefourth of these patients are diagnosed in advanced stages 
leading to poor prospects of long-term survival and cure. ${ }^{2}$ Early detection of cervical cancer is possible with Pap smear tests. It has been found that in many developed countries the annual incidence and prevalence of cervical cancer has decreased by $50 \%-70 \%$ after introduction of population-based screening. ${ }^{2}$ So if women in India undergo screening for cervical cancer, it is possible to detect the cancer in early stages thereby reducing mortality and morbidity.

Screening would be broadly influenced by Knowledge about cervical cancer and knowledge and availability of screening tests among women, Role of health care providers who come in contact with women in hospitals and the sources of information. It is also dependent on Facilities available and the awareness of facilities.

Recently, studies have been reported from India on awareness of cervical cancer and its screening among women. $^{3,4,5}$ Studies exploring the knowledge of the women about cervical cancer have focused either on "nursing staff" working in hospitals or on women in the rural community. 3,4

Three of these studies, which focused on "nursing staff" have reported good awareness about cervical cancer and its screening though the proportion of those who have ever undergone Pap smear ranges from $7 \%$ to $8 \%$, respectively. ${ }^{4}$ Two studies which were done on women in rural communities have also reported awareness of about $72 \%$ though only $2 \%-6.9 \%$ ever had a Pap smear test. ${ }^{3}$ One study among women who attended the outpatient departments (OPDs) has reported low awareness (16\%) though $10 \%$ had ever received Pap test. ${ }^{5}$ Another study from India did not provide any information on knowledge or the proportion of women who have undergone Pap smear test. ${ }^{6}$

A study carried out among college girls, which explored only the knowledge has reported low levels of awareness $(20 \%) .^{7}$ None of the studies have explored the role of the health care providers who come in contact with women and sources of information in the context of early diagnosis. In a study conducted in a rural population of another district of Kerala, almost three-fourth of the study population was aware of cervical cancer and its screening. ${ }^{5}$ This could be probably explained by the difference in the education status of study population in the two studies.

\section{METHODS}

It was a cross-sectional study-observational study. Study setting: Women attending gynecology camps/op clinics held in rural areas of Ernakulam and Thrissur. The study was conducted for one year from date of approval.

Sample size: One study which was conducted in hospitals among women who had come to seek health care reported that $84 \%$ were not aware of cervical cancer. ${ }^{5}$
This was used for sample size calculation as the study setting and population profiles matched with ours.

Using the formula for infinite population $\mathrm{N}=\mathrm{Z}^{2} \mathrm{pq} / \mathrm{d}^{2}$, for $95 \%$ confidence interval and a precision of $10 \%$ we got a sample size of 74 . Accounting for $10 \%$ non-response the total sample size was 83. Women attending cancer detection camps/op associated with Government Medical College Thrissur and Sree Narayana Institute of Medical Sciences Ernakulam

\section{Inclusion criteria}

- Women who are between 25 and 65 years of age (according to the guidelines). ${ }^{2}$

- Women who have given consent for participation in the study.

\section{Exclusion criteria}

- Women who were below 25 or above 65 years of age

- Women who had a prior Hysterectomy and cervix was removed

- Women who did not give consent for participation in the study.

\section{Sampling}

- Non-random sampling.

- Sequential inclusion of the women who met the study criteria.

\section{Study instrument}

A questionnaire was devised collecting following components of information from the subjects:

- Basic sociodemographic profile like age, parity, educational qualification

- Questions to assess knowledge about symptoms of cervical cancer

- Questions to assess the knowledge about cervical cancer screening and prevention

- Doctor as Source of knowledge (like whether doctor educated about cervical cancer, its screening, suggested test for cervical cancer screening during a visit any time in the past). ${ }^{8,9}$

\section{Scoring of questions}

Knowledge about cervical cancer was assessed if the answer to first screen question (Have you heard of/do you know about cervical cancer?) was "yes." Two components of knowledge were assessed:

Symptoms/manifestations of cervical cancer (multiple response question): Irregular menstrual bleeding, bleeding after sexual activity, postmenopausal bleeding, blood stained discharge from vagina, difficulty in passing urine, weight loss, 
Awareness of risk factors for cancer cervix? Early sexual activity, Multiparity, Multiple partners, multiple partners for sexual partner

Each response was given 1 mark. So, the maximum was ten and minimum was zero. The knowledge was graded as: <4 being poor knowledge; 5-6 being satisfactory knowledge and $\geq 7$ being good knowledge.

About screening for cervical cancer: Knowledge about screening for cervical cancer was assessed if the answer to first screen question

- Have you heard of pap smear test?

- How frequent do you need to do Pap smear tests? (once, repeatedly)

- Have you heard of HPV?

- Have you heard of vaccine for Cancer cervix? yes

About Role of Doctor in increasing awareness and uptake of screening for cervical cancer, the following questions were asked.

- Has your Doctor discussed Pap smear testing with you? Yes/No

- Was a Pap smear taken for you ever before? Yes/No

Correct response for questions carried 1 mark. So, the maximum was 6 and minimum was 0 . The knowledge was graded as: <2 being poor knowledge; 2-5 being satisfactory knowledge and $\geq 5$ being good knowledge.

\section{Instrument development}

The questionnaire was peer reviewed by a group of experts from Department of Obstetrics and Gynecology. The questions were scored to help in grading the knowledge.

The study instrument was tried on some women who were attending OPD to check for feasibility and reliability. Changes were made to suit our circumstances. ${ }^{8,9}$

The instrument was translated to local language [Malayalam] by Medical Social Workers and Linguistic Experts.

This was back translated to English by some other linguistic expert who was not familiar with the original version. The back translated version were compared with original version to test for conceptual equivalence. 8,9

\section{Data management and statistical analysis}

Data collected from proforma/ medical records kept in safe custody by principal investigators to be entered into the master chart. The data was analysed using SPSS version 15. Student's independent ' $t$ ' test to know if the differences in the mean knowledge scores across demographic categories like education, employment, age at marriage is statistically significant. $\mathrm{P}^{\prime}<0.05$ considered to be significant.

\section{RESULTS}

The study revealed $32.9 \%$ of women identified discharge per vaginum as most common symptom (Figure 1). Nonmenstrual bleeding was next common known symptom. Urinary symptoms were least reported which was about $4.2 \%$. weight loss was identified as one of the symptoms by $16(7.4 \%)$.

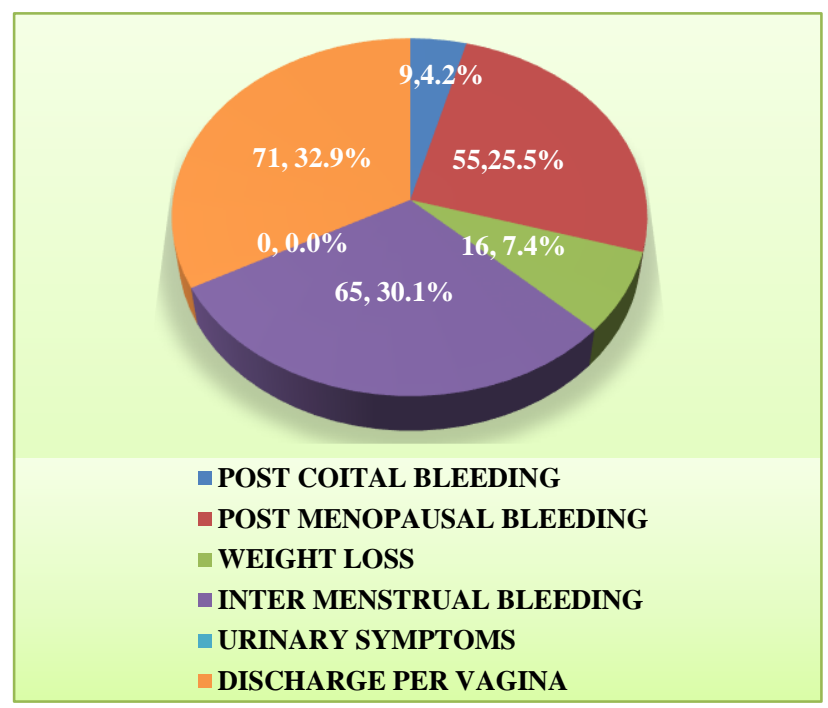

Figure 1: Awareness of symptoms.

When $50.9 \%$ thought multiparty as a risk factor $30 \%$ identified early sexual activity. Figure 2 least aware risk factor was multiple sexual partners for partner.13.4\% identified multiple sexual partners as a risk factor. The study also showed inadequate information regarding pap smear testing among public Only 30\% women of the study were aware of pap smear testing $2.3 \%$ women knew that pap smear screening has to be done repeatedly.

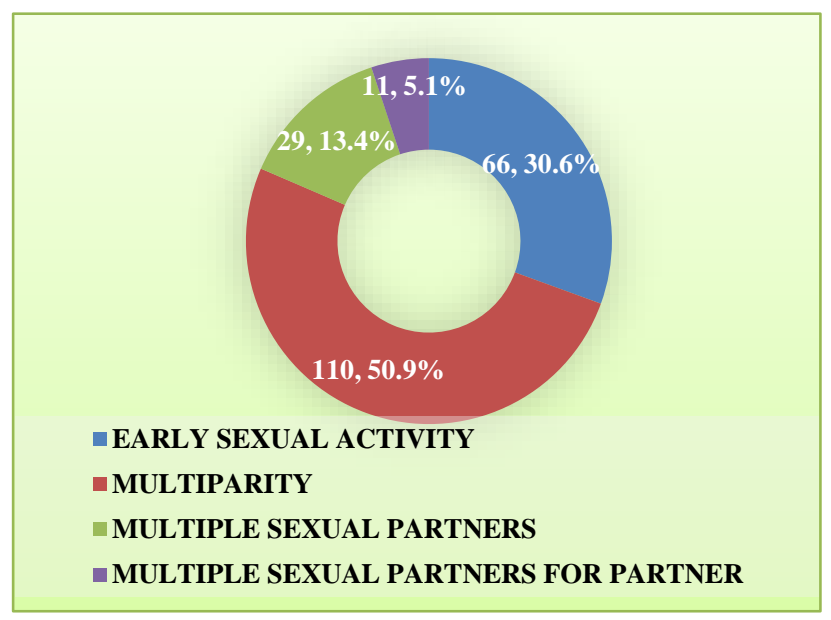

Figure 2: Awareness of risk. 


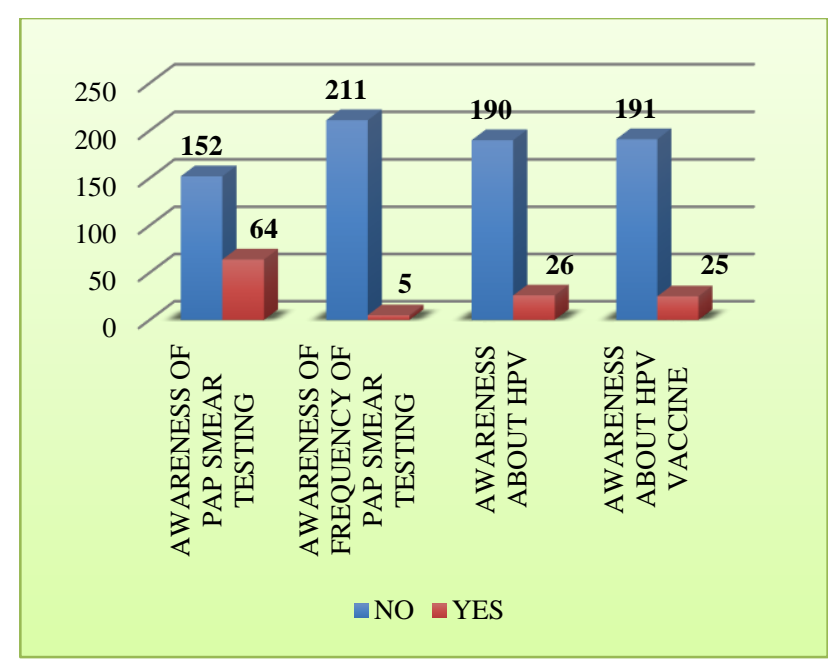

Figure 3: Awareness of pap testing and HPV.

97.7\% women thought pap smear needs to be done only once (Figure 3).

Table 1: Awareness of frequency of pap smear testing in relation to education.

\begin{tabular}{|c|c|c|c|}
\hline \multirow[t]{2}{*}{ Education } & \multicolumn{2}{|c|}{$\begin{array}{c}\text { A wareness of frequency } \\
\text { of pap smear testing }\end{array}$} & \multirow[t]{2}{*}{ Total } \\
\hline & No & Yes & \\
\hline School & 100 & 14 & 114 \\
\hline Graduate & 48 & 50 & 98 \\
\hline Total & 148 & 64 & 212 \\
\hline
\end{tabular}

There was significant difference in awareness of frequency of pap smear testing ( $p$ value $<0.001$ ), awareness of HPV ( $p$ value $=0.001$ ) awareness of HPV vaccine $\mathrm{p}$ value $(0.006)$ with regard to education (Table $1)$.

Table 2: Awareness of HPV in relation to education.

\begin{tabular}{|c|c|c|c|}
\hline \multirow{2}{*}{ Education } & \multicolumn{2}{|c|}{ A wareness of HPV } & \multirow{2}{*}{ Total } \\
\hline & No & Yes & \\
\hline School & 108 & 6 & 114 \\
\hline Graduate & 78 & 20 & 98 \\
\hline Total & 186 & 26 & 212 \\
\hline
\end{tabular}

Chi square $=11.234, \mathrm{df}=1, \mathrm{p}$ value $=0.001$

Table 3: Awareness of HPV vaccine in relation to education.

\begin{tabular}{|llll|}
\hline Education & \multicolumn{2}{|c|}{ A wareness of HPV vaccine } & Total \\
\hline School & No & Yes & 114 \\
\hline Graduate & 107 & 7 & 98 \\
\hline Total & 80 & 18 & 212 \\
\hline
\end{tabular}

Chi square $=7.574, \mathrm{df}=1, \mathrm{p}$ value $=0.006$

Only 6 out of 114 participants was aware of HPV.As many as 20 of 98 graduates were aware of HPV infection indicating more awareness with higher education. A similar level of awareness was seen with regard to HPV vaccine (Table 2).

The awareness of symptoms were also significantly more $\mathrm{p}$ value $<.0 .001$ in graduates compared to school educated (Table 3).

Intermenstrual bleeding was the commonest symptom as identified by graduates whereas postmenopausal bleeding and discharge per vagina were common symptoms reported by matriculates. Post coital bleeding was not identified as a risk factor in the graduate participants (Table 4).

Table 4: Awareness of symptoms in relation to education.

\begin{tabular}{|c|c|c|c|c|c|c|}
\hline \multirow{2}{*}{ Education } & \multicolumn{5}{|c|}{ A wareness of symptoms } & \multirow{2}{*}{ Total } \\
\hline & PCB & PMB & DPV & IMB & WL & \\
\hline School & 9 & 43 & 43 & 14 & 5 & 114 \\
\hline Graduate & 0 & 8 & 28 & 51 & 11 & 98 \\
\hline Total & 9 & 51 & 71 & 65 & 16 & 212 \\
\hline
\end{tabular}

There was no significant difference in knowledge level with regard to parityOF 156 primiparous women 56 was aware of pap smear while 6 out of 53 was unaware. The $p$ value was calculated to be 0.001 (Table 5).

Table 5 awareness of pap smear in relation to parity.

\begin{tabular}{|llll|}
\hline Parity & A wareness of pap smear & Total \\
\hline Nulli/primipara & No & Yes & \\
\hline Multiparity & 47 & 56 & 156 \\
\hline Total & 147 & 6 & 53 \\
\hline
\end{tabular}

Chi square $=11.452, \mathrm{df}=1, \mathrm{p}$ value $=0.001$

24 of primiparous and 2 of 53 multipara knew about HPV. The $p$ value was 0.027 (Table 6). regarding awareness to preventive vaccine was only in 23 primipara out of 156 and 2 of 53 multi para. the p value calculated was 0.033 . $8.3 \%$ of participants already had screening done some time during their life time. Most them were not given proper information by health care workers.8.3\% of doctors only advised pap screening during their consultations (Figure 4). Uptake of Pap smear after awareness program was $100 \%$.

Table 6 awareness of HPV in relation to parity.

\begin{tabular}{|llll|}
\hline Parity & A wareness of HIPV & Total \\
\hline Nulli/primipara & No & Yes & \\
\hline Multiparity & 132 & 24 & 156 \\
\hline Total & 51 & 2 & 53 \\
\hline
\end{tabular}

Chi square $=4.896, \mathrm{df}=1, \mathrm{p}$ value $=0.027$ 


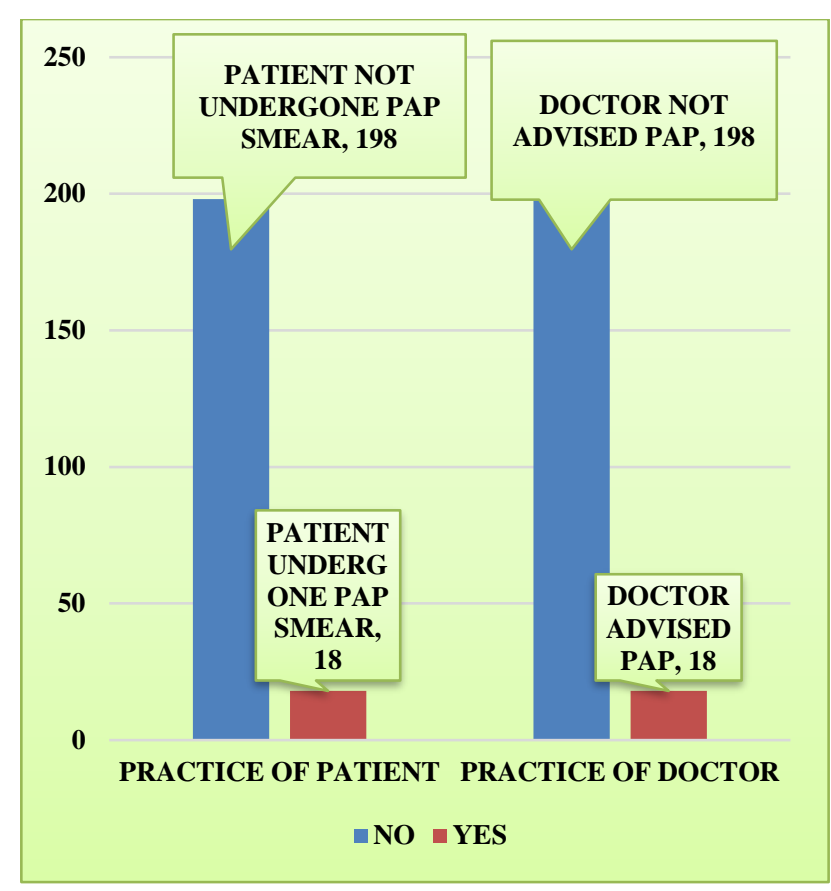

Figure 4: practice of patient and doctor.

Table 7 awareness of HPV vaccine in relation to parity.

\begin{tabular}{|llll|}
\hline \multirow{2}{*}{ Parity } & A wareness & OF HIPV vaccine & \\
& No & Yes & \\
\hline Nulli/primipara & 133 & 23 & 156 \\
\hline Multiparity & 51 & 2 & 53 \\
\hline Total & 184 & 25 & 209 \\
\hline
\end{tabular}

\section{DISCUSSION}

This paper presents socio-demographic variation in the knowledge awareness and practice in relation to prevention of cervical cancer in a rural population in a developing country. Present study showed that $98 \%$ of the women were aware of cervical cancer and $2.3 \%$ were aware of screening and $11.6 \%$ was aware of prevention, where as in a study conducted in rural population of another district of Kerala, almost three-fourth of the study population was aware of cervical cancer and its screening. ${ }^{5}$ This could be probably explained by the difference in the education status of study population in the two studies.

In present study, better education and occupation was found to have significant impact on the awareness of screening which is consistent with findings in other studies. $^{7}$ But education and occupation did not have significant effect on practice of screening which is only $8.3 \% .^{8}$ This is probably because of the poor utilization of the screening services by the women, that significant difference could not be made out. Other study identified that women's knowledge about cervical cancer influenced their screening status. ${ }^{9}$
Age of the women as well as distance to health facility did not have significant effect on utilization of screening services in present study unlike other studies where younger and better educated women were willing to undergo screening. ${ }^{10,11}$ Lack of awareness about screening services, no symptoms and fear of procedure were the reason given by our women for not undergoing screening which is similar to the Kerala study. ${ }^{11}$ Few among present study population, $12.4 \%$ had heard of HPV infection as a risk factor and $11.96 \%$ knew about HPV vaccination. Our results are comparable to the findings from a tertiary rural hospital-based study from Kerala where the Knowledge about Papsmear was only $1.7 \%$ and the knowledge about HPV Vaccine was $0 \% .^{11}$ All women whoever before had a pap smear $(8.3 \%)$ were offered this by their doctor.

In summary, present study population shows poor knowledge about cervical cancer and is unaware of the concept of prevention. If the women had full information on cervical cancer and its prevention and understood the importance of screening their response to screening would be better. Hence, extensive health education to the public is needed regarding cervical cancer even in a highly literate state of India like Kerala.

This study has some limitations and measurement bias. It was a cross sectional study conducted among women attending camps from nearby rural areas and so it is not representative of any particular rural area. The women were of low income and less educated group and so the results may not be generalized to all women, particularly those in urban areas. The method of interviewing rather than self-administered questionnaire may have influenced the results as some of the questions were close ended and some women may have responded in a positive manner to present themselves as knowledgeable.

Though cervical cancer is the leading genital tract cancer among women in India, present study has shown that they are ignorant about this completely preventable disease. Hence, extensive health education to the public is needed to improve their knowledge with an emphasis on the fact that both vaccination and screening are the new standards for prevention of cervical cancer, as HPV vaccination prevents most of the cervical cancer and screening can detect precancerous lesions which can be mitigated by early treatment. Also, utilization of the services of media like television, newspaper and radio can have massive impact on improving the knowledge.

\section{ACKNOWLEDGMENTS}

Authors would like to thank the staff, house surgeons' residents of Department of Obstetrics and Gynecology Sree Narayana Institute of Medical Sciences and Government Medical College Thrissur for their support.

Funding: No funding sources

Conflict of interest: None declared 
Ethical approval: The study was approved by the Institutional Ethics Committee

\section{REFERENCES}

1. Ferlay J, Shin HR, Bray F, Forman D, Mathers C, Parkin DM. Estimates of worldwide burden of cancer in 2008: GLOBOCAN 2008. Int J Cancer. 2010. 2013;15(127):2893-917.

2. Nandakumar A, Gupta PC, Gangadharan P, Visweswara RN. National Cancer Registry Programme (NCRP-ICMR): Development of an atlas of cancer in India. First All India Report. 2001-2002. Vol. I-II, Bangalore: NCRP, 2010.

3. Singhal T. Indian Academy of Pediatrics Committee on Immunisation (IAPCOI)- Consensus Recommendations on Immunization 2008. Indian Pediatr. 2008;45:635-48.

4. Sherris J, Wittet S, Kleine A, Sellors J, Luciani S, Sankaranarayanan R, Barone MA. Evidence-based, alternative cervical cancer screening approaches in low-resource settings. Int Perspect Sexual Reproduct Health. 2009;35(3):147-52.

5. Aswathy S, Quereshi MA, Kurian B, Leelamoni K. Cervical cancer screening: Current knowledge and practice among women in a rural population of Kerala, India. Indian J Med Res. 2012;136(2):20510.

6. Cervical Cancer Awareness Measure Toolkit Version 2.1 Updated 09.02.2011. Cancer Research UK. Available at http:// www.cancerresearchuk.org/
7. Jia Y, Li S, Yang R, Zhou H, Xiang Q, Hu T, Zhang Q, Chen Z, Ma D, Feng L. Knowledge about cervical cancer and barriers of screening program among women in Wufeng County, a high-incidence region of cervical cancer in China. PloS one. 2013;8(7):e67005.

8. Siddharthar J, Rajkumar B, Deivasigamani $\mathrm{K}$, Knowledge and Awareness of Cervical Cancer and Its Prevention in Women Attending a Tertiary Care Hospital J Clinic Diag Res. 2014;8(6):OC01-3

9. Kumar HH, Tanya S. A Study on Knowledge and Screening for Cervical Cancer among Women in Mangalore City Ann Med Health Sci Res 2014; 4(5):751-6.

10. Ackerson K, Gretebeck K. Factors influencing cancer screening practices of underserved women. J Am Acad Nurse Pract. 2007;19(11):591-601.

11. Radha KR, Reena RP. Factors Associated with Delayed Reporting of Invasive Carcinoma Cervix in a Rural Tertiary Care Center. J Obstet Gynecol India. 2016;66(1):417-21.

Cite this article as: Jayaprakash M, Eralil GJ, Jose R, Radha KR, Vijilakshmi AG, Ambikabhai PG. Study on knowledge and practice of screening for cervical cancer among women from rural communities in central Kerala, India. Int J Reprod Contracept Obstet Gynecol 2018;7:4165-70. 